\title{
Endomyocardial Fibrosis in Britain
}

\author{
M. BLACK,* M.B. ; J. M. FOWLER, $†$ M.B., M.R.C.P.
}

Brit. med. F., 1965, 1, 682-686

Fibrosis of the endocardium and myocardium, in the absence of disease of the coronary arteries, still receives scant attention in the standard medical textbooks. It has been recognized for many years as a comparatively uncommon complication of collagen diseases, infiltrative diseases (amyloid, haemochromatosis, von Gierke's disease), beriberi, Friedreich's ataxia and the muscular dystrophies, and alcoholism. The whole subject was well reviewed by Brigden (1957) in the St. Cyres Lecture of 1957. Its existence, in the absence of such associated diseases, was first recognized as a cause of heart failure in East Africans when Bedford and Konstam (1946) described the condition. Following this publication further series were contributed from South and Central Africa (Becker et al., 1953 ; O'Brien, 1954 ; Davies and Ball, 1955), and were thought to delineate a disease process peculiar to the African continent. Pathologically these cases were characterized by a fibrosis of the endocardium and myocardium with a reasonably constant distribution, and occasionally associated with a cellular infiltrate or a fibrinoid change in the smaller coronary arteries. However, these last two features were by no means a constant finding.

That this condition has a world-wide distribution is only now becoming apparent. Articles have appeared describing similar conditions in America (Thomas et al., 1954; McNamara et al., 1959 ; Le Bauer and Bressler, 1962), Ceylon (Nagaratnam and Dissanayake, 1959), Portugal (Coelho and Cortez Pimentel, 1963), Japan (Nakajima et al., 1961), and Jamaica (Stuart and Hayes, 1963). Published cases occurring in Britain so far are few in number (Evans, 1957 ; Penfold, 1957 ; Faruque, 1963 ; St. Mary's Hospital Gazette, 1963), though Lynch and Watt (1957), in describing four cases of adult endomyocardial sclerosis encountered over a period of four years, suggested that it was possible that the condition may be escaping notice. We have collected five similar cases of non-arteriosclerotic endomyocardial fibrosis, one being in an African, from post-mortem material covering a period of approximately two years in a general hospital of 700 beds (P.M. index $70 \%$ of 1,000 deaths a year).

\section{Case 1}

A housewife aged 49 had a six-months history of attacks of breathlessness and wheezing at night, increasing in severity. A gradual onset of exertional breathlessness occurred over this period. At the time of admission she slept on four pillows and was unable to lie flat. She had no cough or haemoptysis, no chest pain, and no history of rheumatic fever. She had had two uneventful pregnancies, the last eight years previously, and was premenopausal.

Examination.-She was well nourished ; no finger-clubbing ; B.P. $150 / 90$; Pulse 112, sinus rhythm not collapsing. Jugular venous pressure (J.V.P.) not raised. No peripheral oedema, liver palpable 2 in. $(5 \mathrm{~cm}$.), smooth and tender. Few bilateral rales posteriorly. Heart apex beat displaced to left; normal impulse. Apical long systolic murmur propagated towards the axilla, not accompanied by a thrill. First sound in the mitral area was normal. Aortic and pulmonary valve closure audible. Protodiastolic third heart sound at apex. Fundi normal except for myopic crescent. Other systems unremarkable.

* Edgware General Hospital. Present address: Department of Medicine, University of New South Wales, Sydney, Australia.

t Edgware General Hospital. Present address: Hospital for Tropical Diseases, University College Hospital, London.
Investigations.-Hb 70\%, W.B.C. 8,900/c.mm., E.S.R. $31 \mathrm{~mm}$. (Westergren). Urine: no cells, no protein; sterile. Protein 6.6 g./ $100 \mathrm{ml}$; ; normal strip. Cholesterel $185 \mathrm{mg} . / 100 \mathrm{ml}$. Chest $x$-ray film: cardiothoracic ratio slightly more than half. E.C.G.: sinus rhythm; left bundle-branch block. Screening: ventricular systole feeble. Barium swallow: oesophagus displaced back by enlarged left auricle.

Course.-An initial response to digitalis and diuretics was followed by relapse. She suddenly developed a pleuritic type of pain in the left side of chest, became cyanosed, and collapsed. There was a change in percussion note at left base posteriorly with numerous rales. She died after being in hospital nine days.

\section{Post-mortem Findings}

A well-nourished woman, with moderate ankle oedema. Brain : Skull, meninges, and brain substance were normal. Heart: The pericardium contained an excess of clear yellow fluid. The heart was increased in size (weight $600 \mathrm{~g}$.), with dilatation and hypertrophy of the left ventricle, dilatation of the. left atrium, and hypertrophy of the right ventricle. The posterior wall of the left ventricle showed irregular endocardial scarring, maximal at the apex, where masses of ante-mortem thrombus were seen in the interstices of the columnae carneae. The endocardial thickening extended into the chordae tendineae of the posterior cusp of the mitral valve, with a resultant shortening of the chordae and distortion of the valve cusp. The coronary arteries contained little atheroma with no evidence of luminal narrowing. There were only a few atheromatous plaques in the aorta. Lungs: The pleural cavities were normal. A large recent infarct was present in the left lower lobe. The remaining lung parenchyma showed moderate congestion and oedema. Liver :

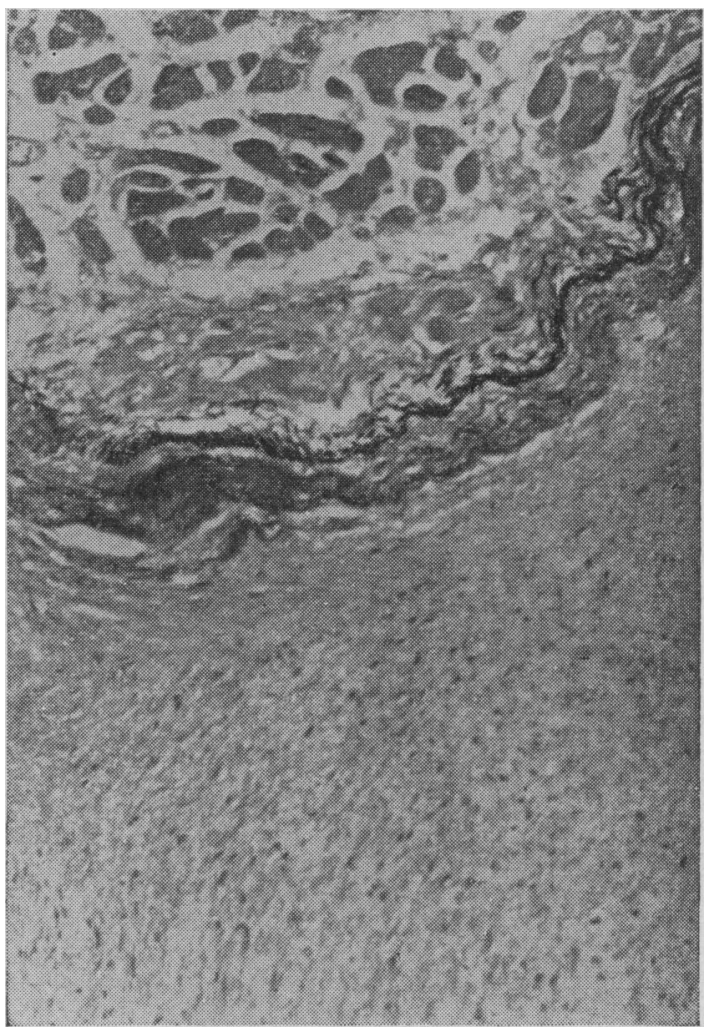

FIG. 1.-Case 1. Endocardial thickening can be seen as a deposition of collagen with the former elastic lamina greatly fragmented. 
This was slightly enlarged (weight $2,050 \mathrm{~g}$.) and sectioning revealed marked congestion. Both spleen and kidneys were congested.

Microscopical Findings.-Examination of the heart showed marked endocardial thickening due to the laying down of collagen fibres parallel to the surface. The elastic lamina showed no reduplication and in some areas was extremely fragmentary (Fig. 1). Patchy myocardial degeneration was seen in the subendocardial region associated with a coarse fibrosis, which lessened towards the epicardial surface. Bundle hypertrophy was present with many bizarre hyperchromatic nuclei. There was no cellular infiltration of the myocardium or endocardium. The blood-vessels appeared atheroma-free and widely patent. The liver showed central congestion, minimal fatty change, and some slight increase in cellularity of the portal tracts.

\section{Case 2}

A clerk aged 55 was well until one month before admission, when, while seated, he developed a sudden attack of breathlessness. This was accompanied by a tight feeling in the chest and dry cough. The breathlessness subsided gradually overnight. Next day he had a similar attack and was admitted to hospital. When seen there was little evidence of cardiac failure and clinical examination was normal. An E.C.G. showed numerous atrial and ventricular extrasystoles, and a chest $x$-ray film revealed slight generalized enlargement of the heart with minimal translucency at both parahilar regions possibly suggestive of clearing pulmonary oedema. After one week in hospital he was discharged. One month later he was readmitted complaining of exertional dyspnoea, orthopnoea, and nocturnal attacks of breathlessness, gradually increasing in severity.

Past History.-He was recruited into the Army aged 35, but was discharged after 18 months because of a "heart murmur." However, at this time he was cycling 40 miles $(64 \mathrm{~km}$.) a day without difficulty. There was no history of rheumatic fever.

Examination.-Pulse 110, with numerous extrasystoles. B.P. $160 / 100$. J.V.P. increased 1 in. $(2.5 \mathrm{~cm}$.). Slight sacral and ankle oedema. No basal rales. Liver not felt. Heart not clinically enlarged. Apical medium systolic murmur not propagated to the axilla or base. Loud mitral first sound. No thrill. No triple rhythm. Fundi normal. Spleen not palpable.

Investigations.-Hb $80 \%$, W.B.C. 11,700/c.mm., normal differential. Urine: faint trace of protein; sterile. Urea $49 \mathrm{mg} . / 100 \mathrm{ml}$. Electrolytes: sodium $130 \mathrm{mEq} / 1$, potassium $5.6 \mathrm{mEq} / 1$., chloride $93 \mathrm{mEq} / \mathrm{l}$., bicarbonate $22 \mathrm{mEq} / 1$. Proteins: $6.4 \mathrm{~g} . / 100 \mathrm{ml}$.; normal strip. S.G.O.T. 17 Sigma-Frankel (S.F.) units. S.G.P.T. 11 S.F. units. Antistreptolysin titre 50 units. W.R. negative. Protein-bound iodine $5.6 \mathrm{mg}$. Blood culture negative. Chest $x$-ray film: heart slightly enlarged; fibrosis in right upper zone; both hilar regions showed loss of translucency suggesting possible pulmonary oedema ; no effusions. E.C.G. : irregular tachycardia with numerous atrial and ventricular extrasystoles.

Course.-The patient ran an intermittent fever which subsided on the administration of tetracycline. Despite treatment with digitalis and diuretics the irregular tachycardia persisted and his heart failure increased. Haemoptysis and chest pain preceded death. He was in hospital three weeks.

\section{Post-mortem Findings}

A well-built, middle-aged man; no peripheral oedema. Brain : Not examined. Heart : A small pericardial effusion was present. There was gross cardiomegaly (weight 700 g.), with marked left ventricular hypertrophy and moderate right ventricular hypertrophy. The right atrium contained much necrotic thrombus in its appendage and on the anterior atrial wall.. Mural thrombus was also present in the interstices of the columnae carneae of the apex of the right ventricle, and in large amounts at the apex and antero-lateral walls of the left ventricle. The myocardium appeared reasonably normal on sectioning, but there was some evidence of moderate endocardial thickening at the sites of adherent thrombus. The valves were normal. The coronary arteries were patent and free of atheroma. The aorta was remarkably atheroma-free. Lungs : A pint $(570 \mathrm{ml}$.) of dark brown fluid was present in the right hemithorax. Both lungs showed evidence of recent and old massive infarction, only the right middle lobe being spared. Many of the larger pulmonary arteries contained organized and organizing thrombus. Liver: This organ was slightly enlarged (weight $2,350 \mathrm{~g}$.), and had a typical nutmeg appearance on sectioning. The spleen contained one large yellow infarct. Kidneys : The right kidney contained one yellow infarct.
Microscopical Findings.-Examination of the heart revealed focal moderate endocardial thickening due to the laying down of collagen (often at right angles to the surface), and reduplication of the elastic lamina. Patchy myocardial degeneration was present in the subendocardial region associated with a coarse fibrosis. Elsewhere in the ventricular wall there was a fine interstitial fibrosis unrelated to muscle damage but associated with dilated capillaries. Musclebundle hypertrophy was present. There was no cellular infiltration of the myocardium and endocardium, and the blood-vessels appeared normal. The liver showed marked central congestion with fibrosis.

\section{Case 3}

A widow aged 70 had a three-weeks history of increasing breathlessness and cough productive of whitish sputum. One week before admission she raised bright-red blood-stained sputum. There was no chest pain. Over this time she noticed swelling of the ankles and started to have breathless attacks at night with inability to lie flat. She was admitted to hospital. She had not had rheumatic fever and had not previously been admitted to hospital.

Examination.-Dyspnoeic and orthopnoeic. Not anaemic. Pulse 104. Regular B.P. 140/100. J.V.P. raised 2 in. $(5 \mathrm{~cm}$.). Gross ankle and sacral oedema. Right pleural effusion with bilateral rales. Liver palpable three fingerbreadths below right costal margin; tender. Apex beat displaced to left, not forceful. Marked gallop rhythm. No murmurs. No ascites. Other systems unremarkable.

Investigations.- $\mathrm{Hb} 83 \%$, W.B.C. 12,500/c.mm. (polymorphs $79 \%$, lymphocytes $12 \%$, monocytes $9 \%$ ). E.S.R. $13 \mathrm{~mm}$. in 1 hour (Westergren). Mid-stream specimen of urine: trace albumin, numerous pus cells; heavy growth of Escherichia coli. Urea 50 mg. $/ 100 \mathrm{ml}$. Proteins $6 \mathrm{~g} . / 100 \mathrm{ml}$.; normal strip. Thymol turbidity 2 units. S.G.O.T. 24 units $/ \mathrm{ml}$. Alkaline phosphatase 22.4 units. Chest $x$-ray film: right pleural effusion; gross generalized enlargement of cardiac shadow; exposed lung fields: hazy shadowing, probably congestion. E.C.G.: sinus rhythm with numerous ventricular extrasystoles; rate $90 / \mathrm{min}$.; partial left bundle-branch block.

Course.-Despite treatment with chlorothiazide and digitalis, and an antibiotic for the infection of the urinary tract, she remained in congestive cardiac failure with some oedema ; she showed no marked diuresis. The pleural effusion was aspirated; it contained a few polymorphs and lymphocytes and protein $1.2 \mathrm{~g} . / 100 \mathrm{ml}$. Two and a half weeks after admission she developed further blood-stained sputum and severe breathlessness, and collapsed and died.

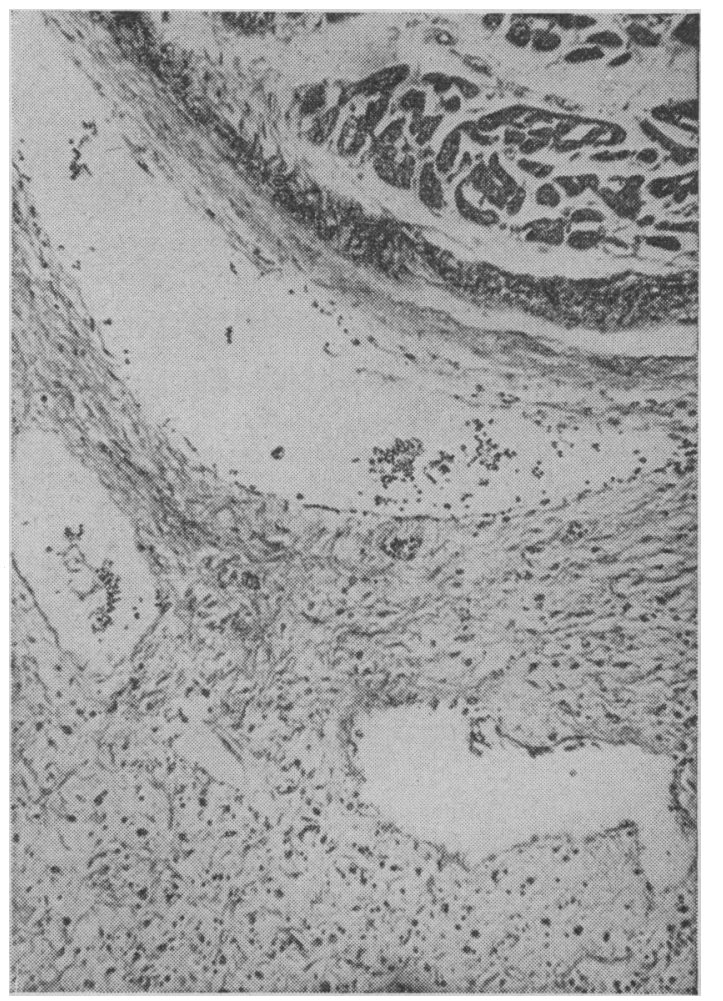

FIG. 2.-Case 3. Thickened endocardium with elastosis and deposition of collagen. 


\section{Post-mortem Findings}

A small, thin, elderly woman; no peripheral oedema. Brain: Not examined. Heart : The pericardium was normal and contained no excess of fluid. The heart was enlarged (weight 690 g.), with hypertrophy of both ventricles. The endocardium of both ventricles showed patches of thickening, with overlying mural thrombus, some of which was undergoing liquefactive necrosis. The valves were normal. The coronary arteries were somewhat sclerotic but did not show much atheromatous change. The aorta showed a mild degree of atheroma. Lungs : There were numerous pleural adhesions in the right hemithorax, which contained about $6 \mathrm{oz}$. $(170 \mathrm{ml}$.) of fluid. The lower lobes of both lungs showed solid areas of infarction of varying ages. The remaining lung parenchyma was congested. Liver: Somewhat reduced in size (weight $840 \mathrm{~g}$.). Sectioning revealed much venous congestion, and blurring of the normal lobular pattern. Spleen : Normal. Kidneys: Normal in size. Sectioning revealed an acute pyelonephritis. The capsules stripped easily.

Microscopical Findings.-Examination of the heart showed a marked focal endocardial thickening due to collagen deposition and reduplication of the elastic lamina (Fig. 2). The myocardium was mainly healthy, although there was patchy fibrosis in the subendocardial region. Muscle bundle hypertrophy was present. There was no cellular infiltration of the myocardium or the endocardium, except where mural thrombus was becoming organized. The liver showed dilatation of the sinusoids, an increase in fibrous tissue in the portal tracts, and occasional fibrous septa connecting with the liver capsule.

\section{Case 4}

A lorry-driver aged 51 had not been feeling well since he developed a cold four weeks before admission. For two weeks he had had exertional breathlessness and noticed a tightness in his chest, not related to exercise. The night before admission he had developed a severe short-lived attack of breathlessness with scant white frothy sputum.

He had not had rheumatic fever. He drank 4 pints (2.3 litres) of beer daily at week-ends.

Examination.-Patient slightly cyanosed and dyspnoeic. B.P. 150/100. Pulse 132, sinus rhythm. Heart not clinically enlarged; loud gallop rhythm. J.V.P. normal. Liver: two fingerbreadths, smooth. Moderate ankle oedema. Percussion note dull with rales at the left base posteriorly. Few right basal rales. Other systems unremarkable.

Investigations.- $\mathrm{Hb} 95 \%$, W.B.C. 8,200/c.mm., normal differential. E.S.R. $13 \mathrm{~mm}$. (Westergren), Electrolytes: sodium $132 \mathrm{mEq} / \mathrm{l}$., potassium $4.0 \mathrm{mEq} / \mathrm{l}$., chloride $93 \mathrm{mEq} / \mathrm{l}$. Urea $27 \mathrm{mg} . / 100 \mathrm{ml}$. Cholesterol $128 \mathrm{mg} . / 100 \mathrm{ml}$. Blood fasting pyruvic acid $1.7 \mathrm{mg} . /$ $100 \mathrm{ml}$. ; one hour after glucose $1.6 \mathrm{mg} . / 100 \mathrm{ml}$. S.G.O.T. 38 units. Protein: 5.4 g. $/ 100 \mathrm{ml}$; strip, slight increase in globulin. Empirical liver-function tests normal. S.G.P.T.: 17 S.F. units. Blood cultures $\times 3$ : no growth. Chest $x$-ray film: heart generally enlarged, diameter 7 in.; lung fields aerated but hazy; probably congested. E.C.G.: sinus rhythm, incomplete right bundle-branch block.

Course.-During his stay in hospital he ran an intermittent fever, and, despite digitalis and diuretics and a period of treatment with tetracycline, the heart failure progressed and his condition deteriorated. He developed a right pleural effusion and became mildly jaundiced. Two days later he died. He was in hospital six weeks.

\section{Post-mortem Findings}

A well-built middle-aged man, with slight jaundice. Brain: The skull, meninges, and brain substance were normal. Heart: There was a small, clear pericardial effusion. The heart was markedly enlarged $(850 \mathrm{~g}$.), with mainly left ventricular hypertrophy, and also some right ventricular hypertrophy. Both atria were dilated. Examination of the cavities of the heart revealed large friable masses of thrombus at the apex of the left ventricle which were situated over shiny white plaques of thickened endocardium. The myocardium appeared quite healthy, without any obvious replacement fibrosis. There was no thrombus present on the right side of the heart. A moderate amount of atheroma was found in the coronary arteries, but no obvious points of severe stenosis or occlusion. The aorta was also moderately atheromatous. Lungs: Both lower lobes con- tained numerous infarcts of varying ages. There was some emphysematous change in the upper lobes. Liver: the portal vein was completely thrombosed. The liver was normal in size, and its substance had a pronounced nutmeg pattern, with two small infarcts in the right lobe. Spleen: Slightly enlarged (370 g.), with multiple yellow infarcts. Kidneys: The right kidney showed almost complete parenchymal destruction by numerous infarcts. The left kidney contained two small infarcts. Alimentary tract: This was normal, apart from extreme congestion of the mesenteric and portal vessels. Examination of the ilio-femoral veins revealed no evidence of thrombosis.

Microscopical Findings.-Examination of the heart was unfortunately not carried out, as the specimen was lost before sections were obtained. However, naked-eye appearances had shown focal endocardial thickening with much overlying thrombus, and little obvious myocardial fibrosis in the ventricular wall. The liver showed an increase of fibrous tissue in the portal tracts, which was most pronounced around the biliary radicles. This was associated with thrombosis and re-canalization of many of the portal veins. There was no increase in cellularity of the tracts. In addition there was extreme central congestion with centrilobular degeneration of liver cells.

\section{Case 5}

This patient was an African priest aged 55 from Calabar, Western Nigeria, who was domiciled in Britain. He had been entirely well until six months before admission, when he developed exertional dyspnoea. There was no history of chest pain. At this time he was admitted to another hospital, where he was found to be orthopnoeic; the heart was clinically and radiologically normal, and examination of the chest showed the signs of consolidation at the right base. An E.C.G. showed no $Q$ waves, no ST changes, but there was $\mathrm{T}$-wave inversion over the left precordial leads. Serial S.G.O.T.s were 30,24 , and 8 units. Despite treatment with digitalis and diuretics, he developed progressive congestive heart failure with cardiac enlargement. Some control of this was achieved, and he was discharged from hospital with mild peripheral oedema and slight exertional dyspnoea. Two weeks later he was unable to walk more than a few steps without becoming breathless; he could not lie flat, and was prone to breathless attacks at night. He was then admitted to Edgware General Hospital.

Examination.-Dyspnoeic, with Cheyne-Stokes respiration. J.V.P. raised to the ears; no peripheral oedema ; numerous bilateral basal rales. Liver felt four fingerbreadths below the costal margin, tender. Heart apex beat in the anterior axillary line. Loud gallop rhythm. Pulse 100 sinus rhythm. Pulsus paradoxus. B.P. 130$100 / 60$. Other systems normal.

Investigations.-Hb. $85 \%$, W.B.C. 7,000/c.mm. (polymorphs $65 \%$, lymphocytes $30 \%$, monocytes $1 \%$, eosinophils $4 \%$ ). Blood urea $60 \mathrm{mg} . / 100 \mathrm{ml}$. Sodium $144 \mathrm{mEq} / 1$; ; potassium $4.1 \mathrm{mEq} / 1$; chloride $106 \mathrm{mEq} / 1$. Glucose-tolerance curve showed mild diabetes. Chest $x$-ray film: gross generalized cardiac enlargement ; lung fields irregular, hazy, density suggesting congestion. E.C.G.: sinus rhythm, occasional ventricular ectopic beats; inverted $T$ wave in S1, S2, V3, and V5, QRS low voltage, QR1, R2, notched R3.

Course.-Despite treatment with digitalis, chlorothiazide, and mersalyl, the heart failure persisted with increasing enlargement of the heart and a loud triple rhythm. The mild diabetes was satisfactorily controlled by diet. He collapsed and died suddenly two and a half months after his admission.

\section{Post-mortem Findings}

A limited post-mortem examination was performed. Middle-aged African; no peripheral oedema. Heart: The pericardium was normal and contained no excess of fluid. The heart weighed $580 \mathrm{~g}$. with considerable hypertrophy and enlargement of both ventricles. The right atrium was markedly dilated. The left ventricle showed endocardial fibrosis, particularly at the apex, where there was a partly organized adherent mural thrombus. The tricuspid valve was slightly dilated; the other valves were normal. There was no evidence of myocardial infarction, and the coronary arteries were not diseased. The main pulmonary arteries were dilated. Lungs: There were numerous pleural adhesions around both lower lobes. Both lungs were congested, especially the lower lobes. The bronchi contained a fair amount of slightly blood-stained frothy sputum. There was no evidence of a recent pulmonary embolus. Liver: This organ appeared enlarged (not weighed), and on sectioning was congested, with a mild nutmeg pattern. 
Microscopical Findings.-Examination of the heart showed collagenous thickening of the endocardium with an intact but not reduplicated elastic lamina. There was much myocardial degeneration in the subendocardial zone, associated with a coarse fibrosis in this region. Muscle-bundle hypertrophy was well marked. Occasional lymphocytes were present in the myocardium, but a heavy cellular reaction was seen only where mural thrombus was becoming organized. The coronary arteries observed were normal. The liver showed centrilobular congestion and some centrilobular parenchymal degeneration.

\section{Summary of Cases}

The ages of the five patients ranged from 49 to 70 years. The length of the disease, from the onset of symptoms until death supervened, was short, varying between 3 weeks and 10 months. In each case heart failure developed without angina, significant hypertension, or history of rheumatic fever being present. Physical examination revealed the signs of heart failure, but generally little else.

Radiological examination of the chest revealed marked cardiac enlargement and, in our one case that was screened, a systolic excursion of markedly diminished vigour; the lung fields appeared congested. There was no absolutely typical E.C.G. finding, though widespread conduction defects with ectopic beats commonly occurred. Evidence of cardiac infarction was lacking, and the left ventricular complexes did not suggest hypertension.

Other ancillary investigations excluded underlying systemic disease. The course of the illness, once established, was relentless, with progression of heart failure despite appropriate drug therapy, and the development of pulmonary and systemic emboli.

Post-mortem examination in all cases revealed a small pericardial effusion with a normal pericardium, and cardiomegaly (weights 580-850 g.). Externally no notching of the ventricular wall was observed. Opening the heart revealed dilatation and hypertrophy of both ventricles, and dilatation and occasional hypertrophy of the atria. The endocardium of the left ventricle showed a patchy or more diffuse thickening, which was most pronounced at the apex, and in two cases extended up the inflow tract, involving the posterior cusp of the mitral valve in one (Case 1 ). The right ventricle was involved in a similar process in two cases. Fibrosis of the underlying myocardium was a prominent feature in three cases and less conspicuous in two. In all five cases significant amounts of ante-mortem thrombus were adherent to the sites of endocardial thickening. Atheroma of the coronary arteries was virtually absent in three cases, and present in moderate amounts in two (Cases 3 and 4).

Histological examination of the endocardial abnormality, carried out in four cases, revealed that the thickening was entirely collagenous in two and partly elastic in two. The elastic lamina of the original endocardial layer could usually be identified, though in the sites of greatest thickening it became very tenuous, and occasionally was absent altogether. Beneath the endocardial lesions myocardial degeneration was apparent, associated with a coarse fibrosis which thinned out towards the epicardial surface. Muscle-bundle hypertrophy was always present, with the large pleomorphic nuclei most common in the subendocardial region. A definite cellular infiltration of the myocardium or endocardium was not seen in any of our cases, away from the areas of organizing thrombus. Nor was there any perivascular "cuffing" with cells, or other evidence of vasculitis. In all instances the coronary arteries appeared atheroma-free and patent.

Changes in other organs were generally secondary to the heart disease. The lungs showed congestive changes and multiple infarcts. The appearances of the latter at postmortem examination often suggested that the process had been going on for longer than was clinically appreciated. Systemic infarction was found in Cases 2 and 4, and in Case
4 no fewer than six organs showed evidence of embolization. Chronic venous congestion of the liver was usually present and in Case 2 had initiated the development of a cardiac cirrhosis. In addition, Cases 2 and 4 showed fibrosis of the portal tract, which in Case 4 was particularly marked around the bile-duct radicle and was associated with thrombosis of the portal vein (a rare occurrence in the absence of a fully developed cirrhosis). This pericholangiolar fibrosis, which has been noted by other workers in the field (D. S. Ridley, personal communication, 1964), is a very occasional associated finding in endomyocardial fibrosis, similar changes also being seen in the pancreas.

\section{Discussion}

The existence of non-arteriosclerotic endomyocardial fibrosis in this country has not been generally accepted as a clinical entity, though occasional cases have been reported. Recent literature suggests that such cases have a world-wide distribution. Davies (1960) reviewed the subject, and, basing his observations on his own material and that of others which he had examined, was able to point out important clinical, pathological, and histological differences between groups of cases related geographically. While never showing the severest pathological changes, our cases present many similarities to the type of disease he and others found in Uganda, and Group II of the cases Edington and Jackson (1963) described from Nigeria.

However, the relationship of our cases with the disease found in Africa and elsewhere is less important than the acceptance of the fact that endomyocardial fibrosis, in the absence of coronary artery disease, exists in this country more commonly than reported cases would suggest.

The problem of diagnosing the condition during life remains one largely of exclusion. Early consideration of the diagnosis is important for the treatment of the complications of the disease. In four of our cases death came as a direct result of pulmonary infarction, and the other (Case 5) showed clinical evidence of a similar occurrence, though post-mortem confirmation was minimal. Anticoagulant therapy has been shown to reduce the incidence of thrombo-embolic complications of myocardial infarction (Honey and Truelove, 1957) and mitral stenosis (Szekely, 1964), and may, by analogy, effect some improvement in the prognosis of this condition. Treatment of the primary condition ultimately depends on what further is discovered of its aetiology and pathogenesis. Steroids have been suggested in the past (Lancet, 1952).

We are unable to do more than comment briefly on the aetiological and pathogenetic aspects of endomyocardial fibrosis. The most frequently suspected aetiological factors have been nutritional deficiency (especially of vitamin $B_{1}$ ), alcohol, various protozoal infections, respiratory viruses, atypical rheumatic fever or other allergic reaction, prolonged localized ischaemia, subendocardial haemorrhage following bouts of anoxia (Williams, 1962), and thrombus adherence with subsequent organization; and Thomas et al. (1954) have suggested that the pathological process may be congenital.

In none of our cases was there clinical or historical evidence of nutritional deficiency, and only one patient (Case 4) drank much alcohol (though never heavily enough to be regarded as an alcoholic). Evidence of a protozoal infestation was lacking in all cases, even in the African. It was not possible to date symptoms from an acute respiratory illness in any case, nor was there any historical, serological, or histological reason for incriminating a rheumatic process. The existence of an area of localized ischaemia as a result of an atheromatous process was only a possibility in Case 4 ; the others were virtually atheroma-free. The remaining suggestions are largely hypothetical and are impossible to prove or disprove from our material. 


\section{Summary}

The increasing recognition of non-arteriosclerotic endomyocardial fibrosis as a significant cause of congestive cardiac failure in adults outside Africa as well as in Africa is noted. Five new cases occurring in Great Britain (one in an African) are added to the mounting literature on the subject. The main clinical and pathological features are summarized, and the suggestion is made that early consideration of the diagnosis may permit some control of the complications of the disease and effect an improvement in the prognosis.

We acknowledge with thanks the permission, freely given, of the physicians of Edgware Hospital to publish these cases, which were under their care. We are grateful to Dr. Hamilton Patterson and Dr. J. P. Williams for further help and criticism.

\section{REFERENCES}

Becker, B. J. P., Chatgidakis, C. B., and Van Lingen, B. (1953). Circulation, 7,345 .
Bedford, E. P., and Konstam, G. L. (1946). Brit. Heart f., 8, 236.

Brigden, W. (1957). Lancet, 2, 1179, 1243.

Coelho, E., and Cortez Pimentel, J.'(1963). Amer. F. Med., 35, 569.

Davies, J. N. P. (1960). Amer. Heart f., 59, 600.

- and Ball, J. D. (1955). Brit. Heart F., 17, 337.

Edington, G. M., and Jackson, J. G. (1963). F. Path. Bact., 86, 333.

Evans, B. (1957). Brit. Heart $\mathcal{f} ., 19,164$.

Evans, B. (1957). Brit. Heart f., 19, 164.

Faruque, A. A. (1963). Lancet, 2, 331.

Honey, G. E., and T

Le Bauer, J., and Bressler, R. (1962). Sth. med. F. (Bgham, Ala.), 55, 694.

Lynch, J. B., and Watt, J. (1957). Brit. Heart f., 19, 173.

McNamara, P. J., Jacobs, W. H., and Jaffé, R. J. (1959). Ann. intern. Med., 50, 1035 .

Nagaratnam, N., and Dissanayake, R. V. P. (1959). Brit. Heart F., 21, 167.

Nakajima, K., Okada, R., and Ueda, H. (1961). Fap. Heart F., 2, 265.

O'Brien, W. (1954). Brit. med. F., 2, 899.

Penfold, J. B. (1957). Lancet, 1, 456.

Penfold, J. B. (1957). Lancet, 1, 456.

St Mary's Hosp. Gaz., 1963, 69, 140.

Stuart, K. L., and Hayes, J. A. (1963).

Thomas, W. A., Randall, R. V., Bland, E. F., and Castleman, B. (1954). New Engl. F. Med., 251, 327.

Williams, J. D. (1962). Unpublished data.

\title{
Fibrinolytic Activity and Thyroid Function
}

\author{
R. HUME,* M.B., M.R.C.P.ED., M.R.C.P.GLASG.
}

Brit. med. F., 1965, 1, 686-688

Hypothyroidism is a condition which is associated with atherosclerotic changes in arteries, especially the coronary, renal, and cerebral arteries (Fishberg, 1924; Douglass and Jacobson, 1957). In spite of this, however, the reported incidence of angina of effort in untreated hypothyroidism is small. Willius and Haines (1925) found only one case out of 162 patients studied, and Smyth (1938) found two cases out of 108 patients. On the other hand, on giving thyroid to such patients the incidence of angina increases to $16 \%$ (Wayne, 1960). Not only is angina unusual, myocardial infarction also seems to be an uncommon event in the untreated case. There is, however, no information in the literature on this aspect of hypothyroidism. During the years 1952 to 19623,026 patients with myocardial infarction were admitted to the Southern General Hospital, Glasgow. Of these, 58 were receiving thyroid for hypothyroidism but none had untreated hypothyroidism.

Smyth (1938), after reviewing the literature, concluded that the number of reported cases of death from myocardial insufficiency in patients with untreated hypothyroidism is remarkably small. Nevertheless, it is well recognized that the overenthusiastic administration of thyroid to such patients carries a risk of precipitating a myocardial infarction (Salter, 1941 ; Wallach et al., 1958 ; Wayne, 1960). It is claimed that the infarction occurs in the absence of a coronary artery thrombus (Wood, 1956). The event is explained on the basis of ischaemic necrosis resulting from the increased metabolic demand of the myocardium as a consequence of thyroid administration and the inability of atheromatous coronary arteries to effect an increased blood supply to the myocardium. However, of nine reported deaths attributed to thyroid administration to previously untreated patients with hypothyroidism and on whom necropsies were performed, four were found to have a demonstrable thrombus in a coronary artery (Willius and Haines, 1925 ; Fahr, 1932 ; Smyth, 1938 ; La Due, 1943 ; Wallach et al., 1958). This is approximately the same proportion of thrombi demonstrable at necropsy in uncomplicated myocardial infarction (Branwood and Montgomery, 1956).

Since it appears as though the hypothyroid patient is in some way spared from the effects of the accompanying arterial disease until thyroid is administered, and as vascular disease

- Department of Medicine, Southern General Hospital, Glasgow.
(Sawyer et al., 1960), in particular acute myocardial infarction (Hume, 1958), has been reported to be associated with reduced fibrinolytic activity, it seemed important to determine whether alterations in thyroid function were associated with changes in fibrinolytic activity.

\section{Material and Methods}

Patients (see Table).-These consisted of 75 female subjects who had been referred to the thyroid clinic at the Western Infirmary for diagnostic radioactive-iodine studies. They were seen on a Monday between 8.45 and 9.15 a.m. prior to the administration of a tracer dose of radioactive iodine for diagnostic purposes. The subjects had had only tea and toast for breakfast. All were out-patients. Blood was withdrawn from an antecubital vein and $9 \mathrm{ml}$. delivered into a warmed graduated centrifuge tube containing $1 \mathrm{ml}$. of $3.8 \%$ sodium citrate. This blood was used for the measurement of fibrinolytic activity, fibrinogen, and cholesterol levels. At the end of the experiment the patients were divided into the following groups on the basis of age and the results of the conventional radioactive-iodine studies. Eight patients were excluded because of equivocal radioiodine results.

Results Expressed as the Means with One Standard Deviation. Fibrinolytic Activity Also Expressed as a Median Because the Distribution Curve was Skewed

\begin{tabular}{|c|c|c|c|c|c|c|}
\hline \multirow{2}{*}{ Group } & \multirow{2}{*}{$\begin{array}{l}\text { No. of } \\
\text { Patients }\end{array}$} & \multirow{2}{*}{$\begin{array}{c}\text { Age } \\
\text { (Years) }\end{array}$} & \multirow{2}{*}{$\underset{(\mathrm{mg} . / 100 \mathrm{ml} .)}{\text { Fibrinogen }}$} & \multicolumn{2}{|c|}{ Fibrinolysis $\%$} & \multirow{2}{*}{$\begin{array}{l}\text { Cholesterol } \\
(\mathrm{mg} . / 100 \mathrm{ml} .)\end{array}$} \\
\hline & & & & Median & Mean & \\
\hline $\begin{array}{l}\text { Ia } \\
\text { Ib } \\
\text { IIa } \\
\text { IIb } \\
\text { III }\end{array}$ & $\begin{array}{r}21 \\
18 \\
13 \\
7 \\
16\end{array}$ & $\begin{array}{l}38 \cdot 7 \pm 6 \cdot 2 \\
59 \cdot 3 \pm 5 \cdot 7 \\
36 \cdot 7 \pm 6 \cdot 8 \\
56 \cdot 1 \pm 5 \cdot 0 \\
56 \cdot 8 \pm 7 \cdot 4\end{array}$ & $\begin{array}{l}238 \cdot 2 \pm 51 \cdot 5 \\
317 \cdot 2 \pm 86 \cdot 4 \\
283 \cdot 3 \pm 64 \cdot 2 \\
275 \cdot 1 \pm 56 \cdot 1 \\
291 \cdot 0 \pm 50 \cdot 9\end{array}$ & $\begin{array}{l}15 \cdot 3 \\
15 \cdot 5 \\
10 \cdot 6 \\
12.9 \\
62.5\end{array}$ & $\begin{array}{l}15 \cdot 3 \pm 4.9 \\
22 \cdot 8 \pm 19 \cdot 2 \\
17 \cdot 6 \pm 18 \cdot 2 \\
26 \cdot 0 \pm 29 \cdot 9 \\
55.9 \pm 33.7\end{array}$ & $\begin{array}{l}173 \cdot 5 \pm 26 \cdot 8 \\
205 \cdot 9 \pm 41 \cdot 1 \\
129 \cdot 7 \pm 23 \cdot 4 \\
129 \cdot 8 \pm 16 \cdot 1 \\
261 \cdot 0 \pm 64 \cdot 1\end{array}$ \\
\hline
\end{tabular}

Group Ia, 21 euthyroid patients under the age of 50 .

Group Ib, 18 euthyroid patients aged 50 and over.

Group IIa, 13 hyperthyroid patients under the age of 50 .

Group IIb, 7 hyperthyroid patients aged 50 and over.

Group III, 16 hypothyroid patients aged 50 and over.

Fibrinogen was prepared by the phosphate-buffer method of Jacques (Biggs and Macfarlane, 1957). Radioiodinated 